Research Article

\title{
Modulation of cytochrome P450 3A4 mediated quinine metabolism in healthy volunteers by two honey samples from different floral and geographical sources
}

\author{
Sharon Iyobor Igbinoba ${ }^{1}$, Cyprian Ogbonna Onyeji ${ }^{2}$, Moses Atanda Akanmu ${ }^{3}$
}

\begin{abstract}
${ }^{1}$ Department of Clinical
Pharmacy and Pharmacy

Administration, ${ }^{2}$ Department of

Pharmaceutical Chemistry,

${ }^{3}$ Department of Pharmacology,

Obafemi Awolowo University,

Ile-Ife, Nigeria
\end{abstract}

Received: 02 March 2016

Accepted: 04 April 2016

\section{*Correspondence to:}

Dr. Sharon Iyobor Igbinoba,

Email: sharonomo2002

@ yahoo.co.uk

Copyright: () the author(s), publisher and licensee Medip Academy. This is an openaccess article distributed under the terms of the Creative Commons Attribution NonCommercial License, which permits unrestricted noncommercial use, distribution, and reproduction in any medium, provided the original work is properly cited.

\begin{abstract}
Background: Honey is widely used both for its nutritional and medicinal benefits and reports exist to suggest it may alter the disposition of conventional drugs whose metabolism is mediated by CYP3A4. The study aimed at investigating the effect of multiple dose administration of honey sourced from two different geographical zones in Nigeria, on an antimalarial, quinine and its CYP3A4 mediated metabolism.

Methods: In a randomized cross-over study, twenty healthy volunteers divided into two groups A and B [A used honey (HA) from Northern and B used honey (HB) from Eastern Nigeria; $n=10$ respectively] received single oral doses of 600 $\mathrm{mg}$ quinine sulphate tablet alone and after 7 days administration of $10 \mathrm{ml}$ of honey (HA or HB) twice daily. Blood samples collected at the $16^{\text {th }}$ hour following quinine administration were subjected to HPLC analysis.

Results: Compared to baseline, $10 \mathrm{ml}$ of honey HA significantly increased $(0.86 \pm 0.22$ versus $1.36 \pm 0.43)(\mathrm{p}<0.05$; Wilcoxon test $)$; mean metabolic ratio of quinine (3-hydroxyquinine/quinine) in group A subjects. On the other hand, administration of honey $\mathrm{HB}$ resulted in a non-significant reduction $(\mathrm{p}>0.05)$ $(0.84 \pm 0.19$ versus. $0.69 \pm 0.34)$ of the metabolic ratio of quinine in group $\mathrm{B}$ volunteers. Also, the geometric mean [95\% CI: $0.63(0.45,0.91)]$ of quinine metabolic ratio in the presence of honey HA alone was significantly increased $(\mathrm{p}=0.02$, $\mathrm{t}$-test $)$.

Conclusions: Honey sample from Northern Nigeria significantly stimulated CYP3A4-mediated quinine metabolism as reflected by an increased metabolic ratio of quinine. In conclusion some honey samples may have the potential to significantly modulate CYP3A4 activity, thus honey effects cannot be generalized.
\end{abstract}

Keywords: Quinine, Honey, CYP3A4, Metabolic ratio, Drug-food interactions

\section{INTRODUCTION}

In recent years, there is a tremendous interest in the possible role of nutrition in prevention of diseases leading to a growing demand of natural products in human diet. ${ }^{1}$ Increasing consumption of medicinal herbs and dietary supplements suggest that, when they are administered in combination with conventional therapeutic drugs, it is likely that constituents in herbal preparations may be substrates, inhibitors, or inducers of Cytochrome P450 and this may have significant impact on the pharmacokinetics of any co-administered drugs metabolized by this system. ${ }^{2}$
From ancient time, honey a natural product has been widely used in traditional medicine to treat a wide range of ailments and complaints and in recent years there is a rise in its use as household nutritional supplement and as sweetener instead of sugar. ${ }^{3-6}$ Honey, apart from being primarily composed of sugar, also contains flavonoids and phenolic compounds such as chrysin, kaempferol, quercetin, pinobanksin, pinocembrin, luteolin, apigenin, genistein, naringenin, hesperetin, P-coumaric acid, gallic acid, ellagic acid, ferulic acid, syringic acid, caffeic acid and vanillic acid, some of which have been shown to increase the activity of CYP3A4 in vitro. ${ }^{7-11}$ Few studies have investigated the influence of honey sourced from different geographical regions on the activities of some 
CYP450 in rats and humans. It is well known that the composition of natural honey varies, depending on many factors such as the geographical areas, source of honeybee food or florals, climate, environmental conditions and the processing it undergoes. ${ }^{1,9,12,13}$ For instance, honey from India has been reported to significantly induce CYP3A in animal models and in man. ${ }^{14-17}$ However two studies in man have found no significant modulating effect of a German and a Nigeria honey on CYP3A4 activity in humans. ${ }^{18,19}$ There is a resurgence of the use of quinine in the treatment of malaria because of resistance development to the other amino quinolones. ${ }^{20}$ There are numerous evidences that suggest metabolism of quinine to 3-hydroxyquinine is mediated by CYP3A4 and may be used for phenotying CYP3A4 activity. ${ }^{21-24}$ Björkhem-Bergman et al recently demonstrated that quinine metabolic ratio was comparable to midazolam clearance in plasma as a measure of CYP3A4-activity and midazolam is a well validated and recommended probe drug for CYP3A activity. $^{25,26}$

This interaction study has dual rationale. Firstly since honey is a highly popular food supplement in Africa, it is necessary to determine its influence on the metabolism of quinine which is useful in the treatment of severe and complicated malaria in sub-Sahara Africa where malaria is endemic. ${ }^{20}$ Secondly, quinine has been validated against midazolam, a well-established probe for CYP3A4 activity. ${ }^{25}$ Modulation of activity of this enzyme by honey provides information on the potential for the honey to influence other CYP3A4 substrates which constitute over $60 \%$ of conventional drugs. ${ }^{27}$ The only available drughoney interaction study of honey from Africa by Igbinoba et al suggested that honey sample from western region of Nigeria did not significantly alter CYP3A-mediated metabolism of quinine in healthy human volunteers though a dose-dependent biphasic effect on the pattern of quinine metabolism was observed. ${ }^{19}$ Indeed Nigeria is a very large country with different climatic condition and vegetation along the different region and geographical spread. Knowing that numerous factors such as climate and floral sources may affect the honey constituents with attendant variation in honey, it was deemed necessary to study samples of honey from other geographical region within Nigeria to know how it will modulate CYP3A4 metabolism of quinine. This present study set out to investigate how honey harvested from beehives in the Northern and Eastern geographical region of Nigeria may affect CYP3A4 mediated metabolism of quinine. The metabolic ratio of quinine (3- hydroxyquinine/quinine) in a $16^{\text {th }}$ hour plasma sample collected in healthy volunteers after quinine administration with and without multiple honey intake was used to assess the influence of honey on CYP3A4 metabolism of quinine. ${ }^{23,28}$

\section{METHODS}

Before the commencement of the study, ethical approval was obtained from the Obafemi Awolowo University teaching hospital complex research ethics board and safety committee. Twenty apparently healthy subjects, comprising of 14 males and 6 females (range; mean \pm SD: age, $19-29$ years; $24.16 \pm 2.87$ years and weight, $45-74 \mathrm{~kg}$; $61.5 \pm 9.92 \mathrm{~kg}$ ) who gave a written informed consent to comply with the study protocol participated in this study. All subjects were healthy according to medical history, laboratory (liver and kidney function test) and clinical investigations. Potential subjects were excluded if on alcohol, on tobacco, pregnant, breast feeding, suffering from chronic disease, on quinine therapy or with known hypersensitivity reaction to quinine or similar agent. From two weeks until the end of the study, the volunteers were told to abstain from taking honey, fruits juices or herbal supplements and quinine.

Honey samples used in the present studies were sourced directly from the beekeepers thus information was obtained about the major floral sources (Table 1) within about 5-10 km of the beehive, presumably the floral the bees fed on. The bees' major floral source for honey sample from Eastern Nigeria was palm tree; Northern Nigeria Honey sample was produced by bees which fed from about four floral sources (Table 1). The honeys were coded: HA (from Kaduna in Northern Nigeria) and HB (from Umudike in Eastern Nigeria).

Table 1: Major flora within the immediate vicinity of the beehive for the honey samples.

\begin{tabular}{|c|c|c|c|c|}
\hline Place/(honey code) & Honey colour & Scientific name & Family & Common name \\
\hline Northern Nigeria (HA) & Light brown & $\begin{array}{l}\text { Butyrospermum } \\
\text { parkii } \\
\text { Parkia biglobosa } \\
\text { Pennisetum glaucum } \\
\text { Sorghum bicolor }\end{array}$ & $\begin{array}{l}\text { Sapotaceae } \\
\text { Mimosaceae } \\
\text { Poaceae } \\
\text { Poaceae }\end{array}$ & $\begin{array}{l}\text { Sheabutter tree } \\
\text { Locustbean tree } \\
\text { Pearl-millet Sorghum }\end{array}$ \\
\hline Eastern Nigeria (HB) & Light brown & Elaei guineensis & Aracaceae & Palm tree \\
\hline
\end{tabular}

Twenty volunteers were randomly divided into two groups $(A$ and $B)$ of ten $(n=10)$ each based on the honey type (HA or HB) to be taken. To investigate the effect of the selected Nigeria honey samples on CYP3A4 activity 
using quinine as the probe drug, a randomized, open label two periods cross over pharmacokinetic design was used with a two-week wash out period allowed between drug administrations. On day 1 of the study, after an overnight fast, each subject in the respective groups (A and B) received a single oral dose of $600 \mathrm{mg}$ of quinine sulphate tablet (Maderich Ltd, Surrey, England) alone or after taking approximately $10 \mathrm{ml}$ of either honey HA or HB, respectively, twice daily for 7 days. In each period, blood samples $(5 \mathrm{ml})$ were collected at the $16^{\text {th }}$ hour post quinine administration.

\section{Method of analysis}

A validated HPLC method reported by Babalola et al but modified by Igbinoba et al was employed in the analysis of quinine and its metabolite, 3 hydroxyquinine in plasma. ${ }^{19,29}$ The Agilent HPLC machine (Agilent 1200 series, Agilent Technologies, Santa Clara, California) used in the analysis was fitted with an isocratic pump (model G1341A) coupled with variable wavelength detector [Agilent Technologies; standard version (model G1341B)] set at $254 \mathrm{~nm}$. Drug and metabolite extraction from $1 \mathrm{ml}$ of plasma (to which had been added $3.0 \mu \mathrm{g} / \mathrm{ml}$ of primaquine as internal standard) was achieved by precipitating with $200 \mu \mathrm{l}$ of perchloric acid $(70 \% \mathrm{w} / \mathrm{w})$ and alkalinisation with $\mathrm{NaOH}$, followed by extraction with diethylether and subsequent back-extraction into 0.1 $\mathrm{M} \mathrm{HCl}$. Chromatographic run was done with a mobile phase composition of methanol: acetonitrile: $0.02 \mathrm{M}$ potassium dihydrogen phosphate buffer (15:15:70) and $74 \mathrm{mmol} / \mathrm{l}$ perchloric acid $(0.64 \mathrm{ml})$, adjusted with $10 \mathrm{M}$ $\mathrm{NaOH}$ to a $\mathrm{pH} 2.6$ and separation was achieved with an Eclipse XDB-C18 reverse phase HPLC column (150x4.6 $\mathrm{mm}$ internal diameter) with a $5-\mu \mathrm{m}$ particle size (Agilent USA). Linear curves were obtained over a range of 1.25$80 \mu \mathrm{g} / \mathrm{ml}$ with a coefficient of determination $\left(\mathrm{R}^{2}\right)$ of over 0.998 for standard curves for quinine and its metabolite, 3-hydroxyquinine. The calibration procedures were as previously reported. ${ }^{19}$ The limit of quantitation was 0.37 $\mu \mathrm{g} / \mathrm{ml}$ and $0.5 \mu \mathrm{g} / \mathrm{ml}$ for quinine and 3-hydroxyquinine, respectively. At concentrations of 0.25 and $4.0 \mu \mathrm{g} / \mathrm{ml}$, the intra-day and inter-day coefficient of variation was not greater than $4 \%$ for both quinine and 3-hydroxyquinine. The recovery was at least $93.9 \%$ for quinine and $73.4 \%$ for 3-hydroxyquinine. The accuracy was between $93.1 \%$ and $105.9 \%$.

\section{Data and statistical analysis}

The effect of honey on CYP3A4 metabolism of quinine was estimated using the 16th hour metabolic ratio (MR) of quinine in plasma as defined below.

$$
\text { Metabolic ratio }=\frac{\text { Plasma concentration of } 3-\text { hydroxyquinine at the } 16 \text { th hour }}{\text { Plasma concentration of quinine at the } 16 \text { th hour }}
$$

Statistical analyses were generated using SPSS for Windows, Version 16.0. Chicago, SPSS Inc. Data were generally expressed as mean $\pm \mathrm{SD}$. In each groups of volunteer (A and $\mathrm{B}$ respectively) a non-parametric statistical test (Wilcoxon matched-pairs signed rank test) was used to determine any significant difference in the mean metabolic ratio of quinine at baseline and in the presence of the respective honey. Also the individual metabolic ratios were log-transformed and the mean difference between pairs of data (log MR quinine alone $\log$ MR quinine and honey) was calculated and presented with the antilog. Corresponding $95 \%$ confidence intervals for the MR were calculated from the antilog of the mean. Statistically differences in the mean MR of the two set of $\log$ transformed data was determined with paired t-test. $\mathrm{P}$ value below 0.05 was considered statistically significant.

\section{RESULTS}

The study started with twenty volunteers but three subjects (two subjects from group A and one from group B) withdrew from the study because of non-compliance to study protocol. (Tables 2 and 3) show the metabolic ratio (mean $\pm \mathrm{SD}$ ) for quinine both at baseline and with ingestion of honey. In group $\mathrm{A}$, quinine mean metabolic ratio significantly increased by $57.63 \%(\mathrm{P}<0.05)$ while in group $\mathrm{B}$ it reduced by $17.4 \%$ and this reduction was not significant $(\mathrm{P}>0.05)$ (Table 2).

Table 2: Summary of mean metabolic (MR) ratio of quinine (3-hydroxyquinine/quinine) following oral administration of $600 \mathrm{mg}$ of quinine sulphate tablets alone or after intake of $10 \mathrm{ml}$ of respective honey samples twice daily for seven days to groups A and B healthy volunteers respectively.

\begin{tabular}{|lccc|c|}
\multicolumn{1}{|c}{ Honey Type and dose } & $\begin{array}{c}\text { MR (3-HQN/QN) } \\
\text { (No honey) }\end{array}$ & $\begin{array}{l}\text { MR } \\
\text { (3-HQN/QN) } \\
\text { (With honey) }\end{array}$ & $\begin{array}{c}\text { MR } \\
\text { (\% change) }\end{array}$ & $\begin{array}{l}\text { P-value } \\
\text { HA; Northern Nigeria (10 ml twice daily) }\end{array}$ \\
\hline HB; Eastern Nigeria $(10 \mathrm{ml}$ twice daily) & $0.86 \pm 0.22$ & $1.36 \pm 0.43$ & $\uparrow 57.63$ & $0.01^{*}$ \\
\hline
\end{tabular}

3-HQN/QN 3-hydroxyquinine/quinine; Values are expressed as mean \pm SD, (Group A; n=8: Group B; n=9), Wilcoxon matched-pairs signed rank test, $* \mathrm{P}<0.05$; 
Table 3: Log-transformed mean metabolic ratio of quinine (3-hydroxyquinine/quinine) following oral administration of $600 \mathrm{mg}$ of quinine sulphate tablets alone or after intake of respective honey.

\begin{tabular}{|lll|c|}
\hline Honey Type and dose & Mean difference $\left(3-\mathbf{H Q N}_{\log }-\mathbf{Q N}_{\log }\right)$ & (95\% CI) & P-value \\
\hline HA; Northern Nigeria (10 ml twice daily for 7 days) & 0.63 & $0.45,0.91$ & $0.02 *$ \\
\hline HB; Eastern Nigeria (10 ml twice daily for 7days) & 1.35 & $0.81,2.24$ & 0.20 \\
\hline
\end{tabular}

(Group A; n=8: Group B; n=9); 3-HQN/QN 3-hydroxyquinine/quinine;

Paired t-test calculated for log-transformed MR of quinine (with and without honey), *Statistically significant $\mathrm{P}<0.05$; CIconfidence interval.

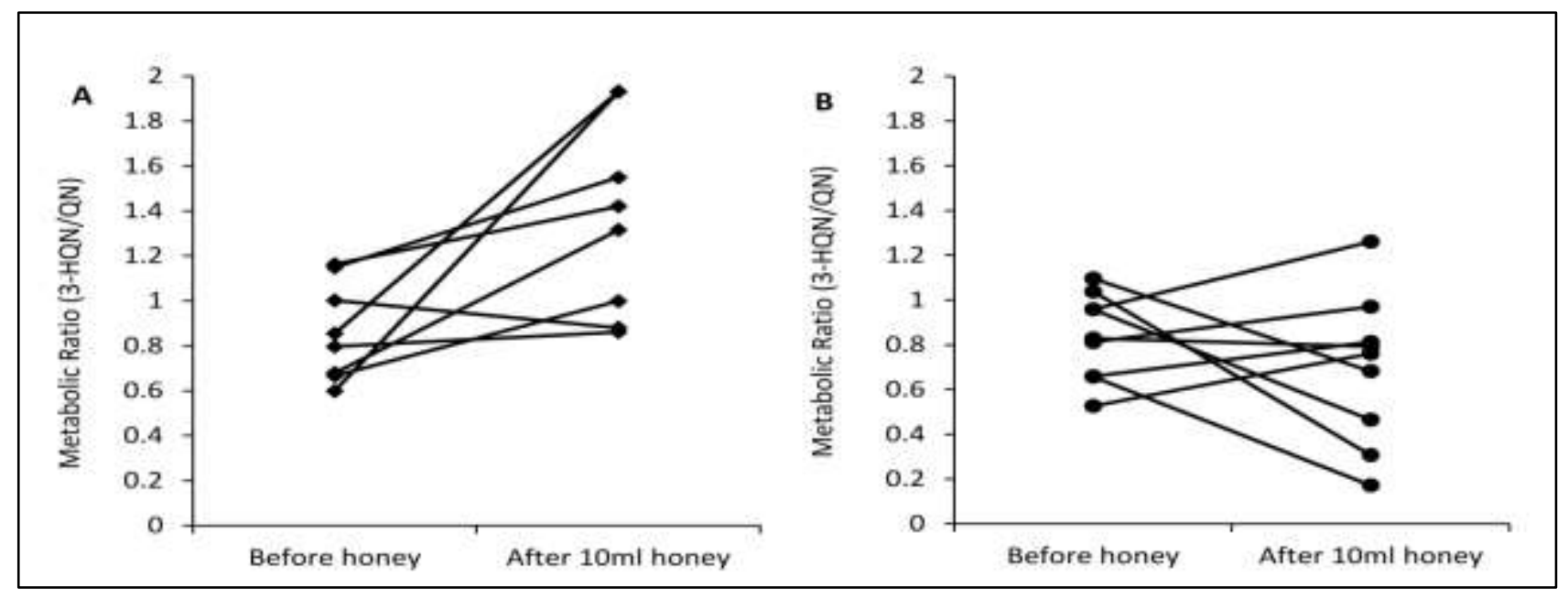

Figure 1: Metabolic ratio of quinine (3-hydroxyquinine/quinine) following oral administration of $600 \mathrm{mg}$ quinine sulphate tablet to healthy volunteers before and after administration of $10 \mathrm{ml}$ of Northern (A) and 10ml of Eastern (B) Nigeria honey twice daily for 7 days [Groups; A: $\mathbf{n}=8$; and B:n=9).

In (Table 3), the $95 \%$ confidence interval (CI) for the logtransformed mean in group A was $0.63(0.45,0.91)$ and was significantly different $(\mathrm{p}=0.02)$ from the metabolic ratio in the absence of honey. In group $\mathrm{B}$, the metabolic ratio of quinine pre- and post-honey intake were comparable $(\mathrm{P}>0.05)$. (Figure 1$)$ shows the metabolic ratio of quinine in the two groups (A and $\mathrm{B}$ ) before and after repeated honey (HA and $\mathrm{HB}$ ) intake respectively. Six out of eight subjects (group A; northern honey) showed increased enzyme activity as reflected by a higher metabolic ratio observed. In volunteers who used eastern honey (group B), less marked stimulatory effect on enzyme activity was observed in about fifty six percent of the volunteers while the remaining forty four percent of the subjects demonstrated inhibitory activity that was more marked (Figure 1).

\section{DISCUSSION}

Using quinine as a marker for CYP3A4 activities, we investigated the effects of two honeys from two different geographical zones in Nigeria on CYP3A4 mediated metabolism in healthy volunteers. A broad range of climate and environmental conditions have been shown to alter the levels of plant chemical composition and their secondary metabolite. ${ }^{30,31}$ Variation in honey composition is well established in literature and the chemical constituents of honey generally reflects the flora of plants that the honey producing bee feed on. ${ }^{9,12,13}$ Thus the two honey samples used in this study were empirically presumed to be different in constituents coupled with the knowledge that the bees that produced the respective honey fed on different floral. The bees which produced the honey from Northern region fed on four different plants while the one from the eastern region was obtained from a research Institute were the bees fed on only palm tree. Determination of the constituents of honey sample used in this study is beyond the scope of the present investigation.

Our results showed that while multiple doses of the honey sample from Northern Nigeria region significantly increased the mean metabolic ratio of quinine at the $16^{\text {th }}$ hour by over fifty seven percent when compared to baseline, the change in mean metabolic ratio of quinine in the presence of honey sample from Eastern Nigerian was not significantly altered. Since quinine has been validated against the clearance of midazolam, a well-established probe for assessing CYP3A-activity in man, findings in this present study may suggest that the honey sample from Northern Nigeria caused a significant induction of CYP3A4 mediated quinine metabolism but honey from Eastern Nigeria did not significantly inhibit CYP3A4 activity. ${ }^{25}$ The result of the honey sample from Northern Nigeria is in agreement with earlier studies where honey from India revealed a significant induction of CYP3Amediated metabolism in rabbits and in healthy volunteers. ${ }^{14-17}$ In the group that used honey from Eastern 
Nigeria, a non-significant inhibitory effect of honey on CYP3A4 activity observed is similar to previous report by Feztner et al where multiple doses of German-sourced honey did not significantly inhibit or alter intestinal or hepatic CYP3A4 metabolism of midazolam in healthy human subjects. $^{18}$

Contrary to the result of honey sample from Northern Nigeria, a very recent quinine-honey interaction study of Nigeria honey sample from western region of Nigeria indicated a non-significant dose dependent biphasic effect on quinine metabolism with a lower dose of honey suggesting stimulation and a higher dose indicative of inhibition in CYP3A4 activity in the same group of healthy volunteers. ${ }^{19}$ Furthermore, six out of the eight subjects (group A) who used Northern honey showed increased enzyme activity as reflected by a higher metabolic ratio post honey intake (Figure 1). In group B (used eastern honey); stimulatory and inhibitory activity on CYP3A4 was comparatively spread among the volunteers. This observed non-uniform pattern of effect of honey on CYP3A4 activities is similar to a previous report on the effect of honey on the activities of CYP2C19 where five volunteers showed increase in metabolic ratio and seven volunteers a decrease in metabolic ratio of dextromethorphan. ${ }^{17}$

Thus far, studies on interaction between honey and CYP3A4 substrates have been carried out using honey from different geographical zones and climatic conditions. Putting together our present results and evidences from previous reports in literature, honey seems to have a potential to exact either a stimulatory or inhibitory effects on CYP3A4 activity with or without significant effect. Thus generalization of effect of honey on CYP3A4 substrates may not be appropriate, more so as literatures abound to support that variation in honey constituents exist. ${ }^{9,12,13}$

\section{CONCLUSION}

In conclusion, the results of this study have shown that the two honey samples studied suggest a variable modulatory effect on CPY3A4 mediated metabolism of quinine to 3-hydroxyquinine activity in man. Honey sample from Northern Nigeria alone significantly altered the metabolic ratio of quinine. Potentially, this alteration may affect the therapeutic action of quinine in malaria patient. Making generalization on the effect of honey from a country can be misleading since honey constituents is influenced by the geographical and floral source that produced it.

\section{ACKNOWLEDGEMENTS}

Author thankful to Prof Chinedum. O. Babalola for the kind donation of Internal standard (Primaquine); Dr Olukemi Taiwo and Mr Dimeji Salau for assisting with sample collection.
Funding: The work was partly supported financially by 'Carnegie Corporation of New York Sponsored Fellowships' for Obafemi Awolowo University Female Staff under the auspices of Centre for Gender and Social Policy Studies, Obafemi Awolowo University, Osun State, Nigeria.

Conflict of interest: None declared

Ethical approval: The study was approved by the Institutional Ethics Committee, (ERC/2011/11/01)

\section{REFERENCES}

1. Baltrusaityte V, Venskutonis PR, Ceksteryte V. Radical scavenging activity of different floral origin honey and beebread phenolic extracts. Food Chem. 2007;101:502-04.

2. Zhou S, Gao Y, Jiang W, Huang M, Xu A, Paxton JW. Interactions of Herbs with Cytochrome P450. Drug Metab Rev. 2003;35:35-8.

3. Erejuwa OO, Sulaiman SA, Wahab MS. Effects of honey and its mechanisms of action on the development and progression of cancer. Molecules. 2014;19:2497-522.

4. Ahmed S, Othman NH. Honey as a potential natural anticancer agent: a review of its mechanisms. Evid Based Complement Alternat Med. 2013;2013:829070.

5. Kassim M, Achoui M, Mustafa MR, Mohd MA, Yusoff KM. Ellagic acid, phenolic acids, and flavonoids in Malaysian honey extracts demonstrate in vitro anti-inflammatory activity. Nutr Res. 2010;30:650-59.

6. Al-Waili NS, Saloom KY, Al-Waili TN, Al-Waili AN, Akmal M, Al-Waili FS, et al. Influence of various diet regimens on deterioration of hepatic function and hematological parameters following carbon tetrachloride: a potential protective role of natural honey. Nat Prod Res. 2006;20:1258-64.

7. Chen L, Mechta A, Berebaum M, Zangerl AR, Egeseth NJ. Honeys from different floral sources as inhibitors of enzymatic browning in fruit and vegetable homogenates. J Agric Food Chem. 2000;48:4997-5000.

8. Gheldof N, Engeseth NJ. Antioxidant capacity of honeys from various floral sources based on the determination of oxygen radical absorbance capacity and inhibition of in vitro lipoprotein oxidation in human serum samples. J Agric Food Chem. 2002;50:3050-5.

9. Yao L, Jiang Y, D'Arcy B, Singanusong R, Datta N, Caffin N, Raymont K. Quantitative high-performance liquid chromatography analyses of flavonoids in Australian Eucalyptus honeys. J Agric Food Chem. 2004;52:210-4.

10. Raucy JL. Regulation of CYP3A4 expression in human hepatocytes by pharmaceuticals and natural products. Drug Metab Dispos. 2003;31:533-9.

11. Liu DY, Yang M, Zhu HJ, Zheng YF, Zhu XQ. Human pregnane $\mathrm{X}$ receptor-mediated transcriptional 
regulation of cytochrome $\mathrm{P} 450 \quad 3 \mathrm{~A} 4$ by some phytochemicals. Med Sci. 2006;35:8-13.

12. Viuda-Martos M, Ruiz-Navajas Y, Fernandez-Lopez J, Perez-Alvarez JA. Functional properties of honey, propolis, and royal jelly. J Food Sci. 2008;73:R117-24.

13. Al-Mamary M, Al-Meeri A, Al-Habori M. Antioxidant activities and total phenolics of different types of honey. Nutri Res 2002;22:1041-47.

14. Koumaravelou K, Adithan C, Shashindran CH, Asad M, Abraham BK. Effect of honey on carbamazepine kinetics in rabbits. Indian $\mathrm{J}$ Exp Biol. 2002;40:560-63.

15. Koumaravelou K, Adithan C, Shashindran CH, Asad M, Abraham BK. Influence of honey on orally and intravenously administered diltiazem kinetics in rabbits. Indian J Exp Biol. 2002;40:1164-8.

16. Sukriti J, Garg SK. Influence of honey on the pharmacokinetics of phenytoin in healthy rabbits. Methods Find Exp Clin Pharmacol. 2003;25:367-70.

17. Tushar T, Vinod T, Rajan S, Shashindran C, Adithan C. Effect of honey on CYP3A, CYP2D6 and CYP2C19 enzyme activity in healthy human volunteers. Basic Clin Pharmacol Toxicol. 2007; 100:269-72.

18. Fetzner L, Burhenne J, Weiss J, Völker M, Unger M, Mikus G, et al. Daily honey consumption does not change CYP3A activity in humans. J Clin Pharmacol. 2011;51:1223-32.

19. Igbinoba SI, Onyeji CO, Akanmu MA, Soyinka JO, Pullela SS, Cook JM, et al. Effect of dehusked Garcinia kola seed on the overall pharmacokinetics of quinine in healthy human volunteers. J Clin Pharmacol. 2015;55:348-54.

20. Achan J, Talisuna AO, Erhart A, Yeka A, Tibenderana JK, Baliraine FN, et al. Quinine, an old anti-malarial drug in a modern world: role in the treatment of malaria. Malar J. 2011;10:144.

21. Zhang H, Coville PF, Walker RJ, Miners JO, Birkett DJ, Wanwimolruk S. Evidence for involvement of human CYP3A in the 3-hydroxylation of quinine. $\mathrm{Br}$ J Clin Pharmacol. 1997;43:245-52.

22. Wanwimolruk S, Paine MF, Pusek SN, Watkins PB. Is quinine a suitable probe to assess the hepatic drug metabolizing enzyme CYP3A?. Br J Clin Pharmacol. 2002;54:643-51.

23. Mirghani RA, Ericsson O, Tybring G, Gustafsson LL, Bertilsson L. Quinine 3-hydroxylation as a biomarker reaction for the activity of CYP3A in man. Eur J Clin Pharmacol. 2003;59:23-8.

24. Kanebratt KP, Diczfalusy U, Bäckström T, Sparve E, Bredberg E, Böttiger Y, et al. Cytochrome P450 induction by rifampicin in healthy subjects: determination using the Karolinska cocktail and the endogenous CYP3A4 marker 4b-hydroxycholesterol. Clin Pharmacol Ther. 2008;84:589-94.

25. Björkhem-Bergman L, Bäckström $T$, Nylén $H$, Rönquist-Nii Y, Bredberg E, Andersson TB, et al. Quinine compared to $4 \beta$-hydroxycholesterol and midazolam as markers for CYP3A induction by rifampicin. Drug Metab Pharmacokinet. 2014;29:352-5.

26. Zhu B, Ou-Yang DS, Cheng ZN, Huang SL, Zhou $\mathrm{HH}$. Single plasma sampling to predict oral clearance of CYP3A probe midazolam. Acta Pharmacol Sin. 2001;22:634-38.

27. Fujita K. Food-drug interactions via human cytochrome P450 3A (CYP3A). Drug Metab Drug Interact. 2004;20:195-217.

28. Christensen M, Andersson K, Dale'n P, Mirghani RA, Muirhead GJ, Nordmark A, et al. Pharmacokinetics and drug disposition the karolinska cocktail for phenotyping of five human cytochrome P450 enzymes. Clin Pharmacol Ther. 2003;73:517-28.

29. Babalola CP, Bolaji OO, Dixon PAF, Ogunbonna FA. Column liquid chromatographic analysis of quinine in human plasma, saliva and urine. $\mathbf{J}$ chromatogr. 1993;616:151-4.

30. Mansell RL, McIntosh CA, Vest SE. An analysis of the limonin and naringin content of grapefruit juice samples collected from Florida state test houses. J Agric Food Chem. 1983;31:156-62.

31. Salick J, Fangb Z, Byg A. Eastern Himalayan alpine plant ecology, Tibetan ethnobotany, and climate change. Global Environ Chang. 2009;19:147-55.

Cite this article as: Igbinoba SI, Onyeji CO, Akanmu MA. Modulation of cytochrome P450 3A4 mediated quinine metabolism in healthy volunteers by two honey samples from different floral and geographical sources. Int J Basic Clin Pharmacol 2016;5:823-8. 